\title{
Excessive adiposity at low BMI levels among women in rural Bangladesh
}

\author{
Saijuddin Shaikh ${ }^{1}$, Jessica Jones-Smith ${ }^{2}$, Kerry Schulze ${ }^{2}$, Hasmot $\mathrm{Ali}^{1}$, Parul Christian ${ }^{2}$, \\ Abu Ahmed Shamim ${ }^{1}$, Sucheta Mehra ${ }^{2}$, Alain Labrique ${ }^{2}$, Rolf Klemm², Lee Wu ${ }^{2}$, Mahbubur Rashid ${ }^{1}$ and \\ Keith P. West $\mathrm{Jr}^{2}$ \\ ${ }^{1}$ The JiV it A Project of Johns Hopkins University, Godown Road, Paschimpara, Gaibandha, Bangladesh \\ ${ }^{2}$ Center for Human Nutrition, Department of International Health, Bloomberg, School of Public Health, Johns Hopkins University, Baltimore, MD, \\ USA
}

(Received 5 March 2015 - Final revision received 18 September 2015 - Accepted 12 October 2015)

Journal of Nutritional Science (2016), vol. 5, e11, page 1 of 9

doi:10.1017/jns.2015.32

\section{Abstract}

Asian populations have a higher percentage body fat $(\% \mathrm{BF})$ and are at higher risk for CVD and related complications at a given BMI compared with those of European descent. We explored whether \%BF was disproportionately elevated in rural Bangladeshi women with low BMI. Height, weight, mid-upper arm circumference, triceps and subscapular skinfolds and bioelectrical impedance analysis (BIA) were measured in 1555 women at 3 months postpartum. $\% \mathrm{BF}$ was assessed by skinfolds and by BIA. BMI was calculated in adults and BMI Z-scores were calculated for females $<20$ years old. Receiver operating characteristic (ROC) curves found the BMI and BMI $Z$-score cut-offs that optimally classified women as having moderately excessive adipose tissue (defined as $>30 \%$ body fat). Linear regressions estimated the association between BMI and BMI Z-score (among adolescents) and \%BF. Mean BMI was 19.2 (SD 2.2) kg/m², and mean \%BF was calculated as 23.7 (SD 4.8 ) \% by skinfolds and 23.3 (SD 4.9 ) \% by BIA. ROC analyses indicated that a BMI value of approximately $21 \mathrm{~kg} / \mathrm{m}^{2}$ optimised sensitivity (83.6\%) and specificity (84.2\%) for classifying subjects with $>30 \%$ body fat according to BIA among adults. This BMI level is substantially lower than the WHO recommended standard cut-off point of BMI $\geq 25 \mathrm{~kg} / \mathrm{m}^{2}$. The equivalent cut-off among adolescents was a BMI Z-score of -0.36 , with a sensitivity of $81.3 \%$ and specificity of $80.9 \%$. These findings suggest that Bangladeshi women exhibit excess adipose tissue at substantially lower BMI compared with non-South Asian populations. This is important for the identification and prevention of obesity-related metabolic diseases.

Key words: Overweight: Obesity: Percentage body fat: BMI: Bangladeshi women: Bioelectrical impedance analysis: Skinfolds

Overweight and obesity are associated with increased risk for morbidity $^{(1,2)}$, disability ${ }^{(3)}$ and mortality ${ }^{(4)}$. Even among lowincome countries, the prevalence of overweight and obesity has increased dramatically over the past three decades ${ }^{(5)}$. The South Asian region has the lowest prevalence of overweight (when defined as $B M I \geq 25 \mathrm{~kg} / \mathrm{m}^{2}$ ) for both men and women $^{(6)}$. In particular, Bangladesh exhibits the lowest mean BMI among females. However, even in Bangladesh, average $\mathrm{BMI}$ has increased since $1980^{(5,6)}$. Furthermore, although chronic energy deficiency and infectious diseases are highly prevalent, $41 \%$ of the disease burden ${ }^{(7)}$ and $52 \%$ of the total mortality is due to non-communicable diseases (excluding injury) ${ }^{(8)}$. Additionally, CVD and diabetes are relatively high for this context and have increased in recent years ${ }^{(9-12)}$.

The combination of very low mean BMI yet substantial non-communicable disease burden may signal that standard BMI-based definitions of overweight do not adequately reflect excess adiposity levels in South Asian populations. For example, comparing white European children with Indian children of the same birth size, Indian children have substantially

Abbreviations: BIA, bioelectrical impedance analysis; ROC, receiver operating characteristic.

* Corresponding author: S. Shaikh, fax +880541 61283, email saiju.jivita@gmail.com

(C) The Author(s) 2016. This is an Open Access article, distributed under the terms of the Creative Commons Attribution licence (http://creativecommons.org/licenses/by/4.0/), which permits unrestricted re-use, distribution, and reproduction in any medium, provided the original work is properly cited. 
higher levels of subcutaneous adiposity and lower levels of abdominal viscera and lean tissue ${ }^{(13)}$. Similar results have been reported among South Asian Indian adult females and males $^{(14)}$. When adiposity was measured by the sum of skinfold measurements, Indian women had a mean estimated body fat of $35.4 \%$ at a BMI of $23.3 \mathrm{~kg} / \mathrm{m}^{2}$; the corresponding values for men were body fat of $21.3 \%$ at a BMI of 21.4 $\mathrm{kg} / \mathrm{m}^{2}$. For comparison, white women have been found to reach an average body fat of $35 \%$ at approximately $\mathrm{BMI} \geq$ $30 \mathrm{~kg} / \mathrm{m}^{2}$.

Data from East and South-East Asian populations (China, Hong Kong, Indonesia, Japan, Singapore, and urban and rural Thailand) compiled by a WHO Expert Committee found higher levels of adiposity and substantial cardiovascular risk at lower BMI for some Asian populations compared with white American and European populations. However, there was significant heterogeneity among Asian populations, and this precluded the establishment of one cut-point for all Asian populations. As an alternative, 'health action points' of $\mathrm{BMI}>23$ and $27.5 \mathrm{~kg} / \mathrm{m}^{2}$ were established since the risk for CVD was higher among some Asian populations at a BMI lower than the traditional WHO cut-off points ${ }^{(15)}$.

Notably, the South Asian region, including countries such as Bangladesh, India and Pakistan, was not represented in the analyses by the expert committee due to the lack of direct measures of fatness in regional studies. However, using indirect measures, evidence from India ${ }^{(14)}$ and from South Asians living in New Zealand ${ }^{(16)}$ suggests that the level of body fat at a given BMI may be substantially higher for South Asians even compared with other Asian populations. Our goal was to add to this literature by examining how BMI corresponds to body fat percentage among a large sample of rural Bangladeshi women of reproductive age. Furthermore, we improve upon the existing South Asian studies by utilising bioelectrical impedance with a population-specific body fat percentage equation derived from comparison with ${ }^{2} \mathrm{H}_{2} \mathrm{O}$ dilution ${ }^{(17)}$. Among rural Bangladeshi women, we investigate cut-off levels of BMI for defining overweight that coincide with commonly used percentage body fat categorisations.

\section{Subjects and methods}

This study was comprised of participants in a substudy that was nested within a cluster randomised, double-masked, placebo-controlled trial designed to investigate the impact of weekly vitamin $A$ or $\beta$-carotene supplementation on maternal and infant health and survival conducted at the JiVitA Maternal and Child Health and Nutrition Research Project in two rural districts of northwest Bangladesh ${ }^{(18)}$. Substudy participants (approximately $5 \%$ of all women in the original trial) were selected based on area of residence. In the trial, women were enrolled in early pregnancy and followed, through regular visits, to 3 months postpartum. Among other more intensive assessments conducted among women in the substudy, anthropometric status and bioelectrical impedance analysis (BIA) were measured at 3 months postpartum. Prediction equations from resistance measures obtained from BIA were developed against the ${ }^{2} \mathrm{H}_{2} \mathrm{O}$ dilution method (reference method) for calculating body water, from which estimates of body composition were derived based on assumptions regarding the hydration status of fat-free $\operatorname{mass}^{(19)}$.

Sociodemographic characteristics, such as maternal education, employment, living standard index and parity, were collected using a structured questionnaire, and age was calculated at each visit by subtracting birth date from the date of the visit. All anthropometric measurements were completed in the home by trained and routinely standardised female anthropometrists.

Weight with light clothing was measured on solar-powered SECA digital scales to the nearest $200 \mathrm{~g}$ (SECA UNICEF Electronic Scale 890). Standing height was measured to the nearest $0.1 \mathrm{~cm}$ using a portable Harpenden Pocket Stadiometer (Cromwell), modified with a spirit level affixed to the cross-bar to position subjects along the Frankfort plane. Skinfold thickness (triceps and subscapular) was measured with Holtain calipers (Holtain Ltd) to the nearest $0.2 \mathrm{~mm}$. Mid-upper arm circumference was measured to the nearest $0 \cdot 1 \mathrm{~cm}$ using a non-stretch insertion-type measuring tape manufactured by JiVitA. Quality control of anthropometry data was monitored by a quality-control team that was extensively trained and standardised. Inter- and intra-observer technical error of measurement was calculated, and found to be lower than reference cut-off points ${ }^{(20)}$. All measurements (except weight) were taken three times and median values were used for analysis.

Resistance (R) and reactance (Xc) were measured in the home using a single-frequency portable bioelectrical impedance analyser (Quantum II RJL System). Details of the measurement procedure have been previously reported ${ }^{(17)}$.

Fat mass was calculated using two methods: skinfold method and bioelectrical impedance analysis method. For the skinfold method, first density was calculated using skinfold thickness from the logarithm of total skinfold thickness (triceps + subscapular) $^{(14)}$ and then percentage body fat was calculated from density using Siri's equation $(1956)^{(21)}$ :

$$
\text { Percentage fat }=((4 \cdot 95 / \text { density })-4 \cdot 50) \times 100
$$

For the BIA method, we calculated percentage fat from BIA as follows. Total body water was calculated using the published equation ${ }^{(19)}$ which was developed in women at 3 months postpartum in the same community. Fat-free mass (FFM) was derived from total body water by using the hydration factor $0 \cdot 732^{(22,23)}$.

$$
\text { Calculated fat mass }=\text { total body weight }- \text { FFM. }
$$

Percentage fat mass $=($ fat mass $\mathrm{kg} /$ body weight $) \times 100$.

BMI was calculated using the formula weight $(\mathrm{kg}) /$ height squared $\left(\mathrm{m}^{2}\right)$. Among females under the age of 20 years $(n$ 546), we also calculated age- and sex-specific BMI Z-score using the WHO Growth Reference Charts ${ }^{(24)}$.

This study was conducted according to the Declaration of Helsinki; all study protocols were approved by the Johns Hopkins Bloomberg School of Public Health Institutional 
Review Board. All included participants provided informed consent.

\section{Definition of excess body fat}

Overweight and obesity are characterised by an excess of body fat or adiposity and this excess adiposity is associated with the increased risk for co-morbidities. Hence, the definition of overweight and obesity should correspond to an amount of body fat that is considered excessive and associated with increased risk for co-morbidities. There is a debate regarding the lower limit of body fat for defining overweight and obesity. However, Deurenberg et al. ${ }^{(25)}$ have produced age- and sexspecific formulas that indicate that, for a 25 -year-old white female, a BMI of $25 \mathrm{~kg} / \mathrm{m}^{2}$ would be expected to correspond to a body fat of $30 \%$, while a BMI of $30 \mathrm{~kg} / \mathrm{m}^{2}$ would correspond to approximately $35 \%$ body fat. Too few women in this sample had a body fat percentage that was $>35 \%$; therefore, in this study, $>30 \%$ body fat in females (both adolescents and adults) was used as the cut-off for defining overweight or moderately excessive adiposity.

\section{Statistical analysis}

We calculated the frequency distributions of key demographic characteristics of the study population. Pearson's correlation coefficients were calculated between BMI and percentage body fat according to both the skinfold method and the BIA method. Scatterplots were produced to visually assess these relationships.

To assess the BMI and BMI Z-score cut-offs that optimally classified women as overweight according to their body fat percentage $(\leq 30 \%$ or $>30 \%)$ by the skinfold method and the BIA method, we used receiver operating characteristic (ROC) curve analysis. In ROC analysis, the sensitivity and specificity across a spectrum of cut-offs for BMI/BMI Z-score are calculated. We used the ROC analysis to find the BMI and BMI $Z$-score values that resulted in maximising the true positive rate (sensitivity) and minimising the false positive rate $(1$ - specificity), or equivalently, the value that maximises both sensitivity and specificity. The true positive rate (sensitivity) was plotted against the false positive rate (1 - specificity) across the range of values from the comparison diagnostic test. We also estimated the AUC to assess the overall performance of the BMI and BMI $Z$-score for classifying excessive adiposity. The AUC reflects the probability that the diagnostic test will classify individuals correctly ${ }^{(26)}$. The ROC analysis was conducted separately for women under and above 20 years, since a substantial proportion of our population was between 14 and 19 years and since age- and sex-specific $Z$-scores, rather than BMI, are typically used to classify weight status at this age.

Finally, a linear regression between BMI/BMI Z-score and percentage body fat was performed to assess the magnitude of the association between BMI and body fat. Lowess plots were visually assessed to evaluate if it was reasonable to model these as linear relationships. In addition, squared terms for BMI/BMI Z-score were tested and retained in the models if statistically significant.
In supplementary analyses, we used $t$ tests to compare the anthropometrics of our study population with previously published results.

Analyses were performed using STATA 11.0 intercooled version (STATA Corporation) statistical software. The significance level was set at $<0 \cdot 05$.

\section{Results}

For this substudy, 2668 pregnant women were enrolled during their first trimester. Of them, 1861 women were enrolled at 3 months postpartum period and 1602 women agreed to participate in this study. Of these women, 1555 had completed anthropometries and BIA. Of the total sample, 35.1\% (n 546) were adolescents (age $<20$ years). Demographic characteristics according to age, as well as by BMI and body fat status, are shown in Tables 1 and 2. Almost half of the adult women $(46.5 \%$ ) had no formal education (Table 1); this was lower among adolescents where $22.6 \%$ had no formal education (Table 2). Approximately $20 \%$ of adult women, but $90 \%$ of adolescents, were primiparous.

Among adult women, compared with their representation in the total population, women with a secondary education were overrepresented among those with $\mathrm{BMI} \geq 23 \mathrm{~kg} / \mathrm{m}^{2}$ and body fat $>30 \%$, while those with no formal education were overrepresented among those with BMI $<18.5 \mathrm{~kg} / \mathrm{m}^{2}$ and body fat $<30 \%$. These differences were far less dramatic among adolescents (Tables 1 and 2). On the other hand, for both adult and adolescent women, those in the highest quartile of the living standard index were overrepresented in the highest BMI and body fat categories.

The correlation between BMI and body fat percentage as measured by BIA was $0.68(P<0.001)$ among adults and $0.54(P<0.001)$ among adolescents (using BMI $Z$-score) (Fig. 1(a) and (b)). The correlation between BMI/BMI $Z$-score and body fat percentage estimated by skinfolds was $0.76(P<0.001)$ among adults and $0.61(P<0.001)$ among adolescents (Fig. 1(c) and (d)). The relationship between BMI and body fat percentage was more variable for body fat measured by BIA than by the skinfold method. The linear regression models indicated that each one unit higher BMI was associated with higher body fat of 1.8 percentage points by the skinfold thickness method and 1.5 percentage points by the BIA method in study women (Table 3). Analogous models for BMI $Z$-scores among participants $<20$ years old indicate that a one-unit change in BMI $Z$-score was associated with a higher body fat of 3.3 percentage points by the skinfold thickness method and 3.2 percentage points by the BIA method (Table 3). The squared term for BMI Z-score was significant in this model and positive indicating increasing magnitudes of association at higher BMI $Z$-score levels. The larger numbers for BMI $Z$-scores stem from the fact that a one-unit increase in $Z$-score is bigger than a one-unit increase in BMI.

The ROC curve analysis indicated that the BMI value that maximised sensitivity and specificity with the skinfold method for body fat calculation among adults was $20.9 \mathrm{~kg} / \mathrm{m}^{2}$, which had a sensitivity of $86.5 \%$ and specificity of $87.7 \%$. AUC was 0.95. The analogous value among adolescents was a BMI 
Table 1. Demographic characteristics of study participants according to age, BMI and body fat status: women aged 20 years and above

(Numbers and percentages; mean values and standard deviations)

\begin{tabular}{|c|c|c|c|c|c|c|c|c|c|c|c|c|c|c|c|c|}
\hline \multirow[b]{3}{*}{ Variables* } & & & \multicolumn{6}{|c|}{ BMI $\left(\mathrm{kg} / \mathrm{m}^{2}\right)$} & \multicolumn{4}{|c|}{ Fat percentage $\dagger$} & \multicolumn{4}{|c|}{ Fat percentage $\ddagger$} \\
\hline & \multicolumn{2}{|c|}{ Overall ( $n$ 1009) } & \multicolumn{2}{|c|}{$<18.5(n 374)$} & \multicolumn{2}{|c|}{$\begin{array}{c}18.5-22.9 \\
(n 560)\end{array}$} & \multicolumn{2}{|c|}{$\geq 23(n 74)$} & \multicolumn{2}{|c|}{$\leq 30 \%(n 882)$} & \multicolumn{2}{|c|}{$>30 \%(n 126)$} & \multicolumn{2}{|c|}{$\leq 30 \%(n 898)$} & \multicolumn{2}{|c|}{$>30 \%(n 110)$} \\
\hline & $n$ & $\%$ & $n$ & $\%$ & $n$ & $\%$ & $n$ & $\%$ & $n$ & $\%$ & $n$ & $\%$ & $n$ & $\%$ & $n$ & $\%$ \\
\hline \multicolumn{17}{|l|}{ Education } \\
\hline None & 468 & $46 \cdot 5$ & 197 & $52 \cdot 8$ & 255 & 45.5 & 16 & $21 \cdot 6$ & 438 & 49.7 & 30 & $23 \cdot 8$ & 435 & 48.5 & 33 & $30 \cdot 0$ \\
\hline Primary & 226 & $22 \cdot 4$ & 85 & $22 \cdot 8$ & 131 & 23.4 & 10 & 13.5 & 198 & 22.5 & 28 & $22 \cdot 2$ & 202 & 22.5 & 24 & $21 \cdot 8$ \\
\hline$\geq$ Secondary & 313 & $31 \cdot 1$ & 91 & 24.4 & 174 & 31.1 & 48 & 64.9 & 245 & 27.8 & 68 & 54.0 & 260 & 29.0 & 53 & 48.2 \\
\hline \multicolumn{17}{|l|}{ Employed } \\
\hline No & 541 & 53.7 & 196 & $52 \cdot 4$ & 310 & 55.4 & 35 & $47 \cdot 3$ & 474 & 53.7 & 67 & $53 \cdot 2$ & 488 & 54.3 & 53 & $48 \cdot 2$ \\
\hline Yes & 467 & $46 \cdot 3$ & 178 & 47.6 & 250 & 44.6 & 39 & $52 \cdot 7$ & 408 & $46 \cdot 3$ & 59 & $46 \cdot 8$ & 410 & 45.7 & 57 & $51 \cdot 8$ \\
\hline \multicolumn{17}{|l|}{ Parity } \\
\hline 0 & 200 & $19 \cdot 8$ & 64 & $17 \cdot 1$ & 119 & 21.3 & 17 & 23.0 & 173 & 19.6 & 27 & 21.4 & 180 & $20 \cdot 0$ & 20 & $18 \cdot 2$ \\
\hline 1 & 315 & $31 \cdot 3$ & 118 & 31.6 & 176 & 31.4 & 21 & $28 \cdot 4$ & 280 & 31.8 & 35 & $27 \cdot 8$ & 280 & $31 \cdot 2$ & 35 & 31.8 \\
\hline$\geq 2$ & 493 & 48.9 & 192 & $51 \cdot 3$ & 265 & 47.3 & 36 & 48.6 & 429 & 48.6 & 64 & 50.8 & 438 & 48.8 & 55 & $50 \cdot 0$ \\
\hline Breastfed & 712 & 99.6 & 256 & 99.6 & 413 & 99.5 & 43 & $100 \cdot 0$ & 640 & 99.5 & 72 & $100 \cdot 0$ & 633 & 99.5 & 79 & $100 \cdot 0$ \\
\hline Did not perform physical labour§ & 677 & $69 \cdot 2$ & 243 & $67 \cdot 3$ & 384 & 70.5 & 50 & $69 \cdot 4$ & 586 & 68.5 & 91 & $74 \cdot 6$ & 603 & 69.0 & 74 & $71 \cdot 2$ \\
\hline \multicolumn{17}{|l|}{ LSI\| } \\
\hline Lowest & 278 & $27 \cdot 6$ & 132 & $35 \cdot 3$ & 142 & $25 \cdot 4$ & 4 & 5.4 & 267 & $30 \cdot 3$ & 11 & 8.7 & 260 & 29.0 & 18 & $16 \cdot 4$ \\
\hline 2 & 248 & $24 \cdot 6$ & 106 & $28 \cdot 3$ & 132 & 23.6 & 10 & 13.5 & 233 & $26 \cdot 4$ & 15 & 11.9 & 237 & 26.4 & 11 & $10 \cdot 0$ \\
\hline 3 & 240 & 23.8 & 85 & $22 \cdot 7$ & 142 & $25 \cdot 4$ & 13 & 17.6 & 214 & 24.3 & 26 & $20 \cdot 6$ & 211 & 23.5 & 29 & 26.4 \\
\hline Highest & 242 & $24 \cdot 0$ & 51 & 13.6 & 144 & $25 \cdot 7$ & 47 & 63.5 & 168 & 19.1 & 74 & 58.7 & 190 & $21 \cdot 2$ & 52 & 47.3 \\
\hline \multicolumn{17}{|l|}{ Age (years) } \\
\hline Mean & 26 & & 26 & & 26 & & 28 & & 26 & & 28 & & 26 & & 27 & \\
\hline SD & 5.5 & & $5 \cdot 8$ & & $5 \cdot 2$ & & $6 \cdot 2$ & & $5 \cdot 4$ & & 5.9 & & $5 \cdot 6$ & & 5.4 & \\
\hline \multicolumn{17}{|l|}{ Weight (kg) } \\
\hline Mean & 43.6 & & 38.8 & & $45 \cdot 0$ & & $56 \cdot 6$ & & $42 \cdot 2$ & & 53.0 & & $42 \cdot 4$ & & 53.0 & \\
\hline SD & $6 \cdot 2$ & & $3 \cdot 1$ & & $4 \cdot 3$ & & $6 \cdot 2$ & & 4.8 & & $7 \cdot 0$ & & $5 \cdot 0$ & & $7 \cdot 2$ & \\
\hline \multicolumn{17}{|l|}{ Height (cm) } \\
\hline Mean & 149.6 & & 149.5 & & 149.5 & & $150 \cdot 6$ & & 149.4 & & 150.7 & & 149.4 & & $151 \cdot 1$ & \\
\hline SD & 5.1 & & 4.9 & & 5.4 & & 4.9 & & 5.1 & & 5.1 & & $5 \cdot 1$ & & 5.0 & \\
\hline
\end{tabular}

LSI, living standard index.

* Of the total analytic sample $\geq 20$ years old, missing information on these descriptive characteristics was as follows: education $n$ 2; employed $n 1$; parity $n 1$; breastfeeding $n 296$; physical labour $n 31$; LSI $n$ 1. $\dagger$ Fat percentage measured by the skinfold thickness method.

Fat percentage measured by the bioelectrical impedance analysis method.

was defined as carrying heavy objects or working in the fields or husking grain at least $1 \mathrm{~d}$ during the past week of visit.

ISI is expressed as quartiles. 
Table 2. Demographic characteristics of study participants according to age, BMI and body fat status: women aged under 20 years

(Numbers and percentages; mean values and standard deviations)

\begin{tabular}{|c|c|c|c|c|c|c|c|c|c|c|c|c|c|c|c|c|}
\hline \multirow[b]{3}{*}{ Variables* } & & & \multicolumn{6}{|c|}{ BMI Z-score } & \multicolumn{4}{|c|}{ Fat percentage $\dagger$} & \multicolumn{4}{|c|}{ Fat percentage $\ddagger$} \\
\hline & \multicolumn{2}{|c|}{ Overall $(n 546)$} & \multicolumn{2}{|c|}{$<-1(n$ 226) } & \multicolumn{2}{|c|}{$\begin{array}{c}\geq-1 \text { and }<0 \\
\quad(n 267)\end{array}$} & \multicolumn{2}{|c|}{$\geq 0(n 53)$} & \multicolumn{2}{|c|}{$\leq 30 \%(n 529)$} & \multicolumn{2}{|c|}{$>30 \%(n 17)$} & \multicolumn{2}{|c|}{$\leq 30 \%(n 514)$} & \multicolumn{2}{|c|}{$>30 \%(n 32)$} \\
\hline & $n$ & $\%$ & $n$ & $\%$ & $n$ & $\%$ & $n$ & $\%$ & $n$ & $\%$ & $n$ & $\%$ & $n$ & $\%$ & $n$ & $\%$ \\
\hline \multicolumn{17}{|l|}{ Education } \\
\hline None & 123 & 22.6 & 46 & 20.4 & 67 & $25 \cdot 2$ & 10 & 18.9 & 122 & 23.1 & 1 & 5.9 & 118 & 23.0 & 5 & $15 \cdot 6$ \\
\hline Primary & 123 & 22.6 & 54 & 23.9 & 57 & 21.4 & 12 & $22 \cdot 6$ & 119 & 22.5 & 4 & 23.5 & 113 & 22.0 & 10 & 31.3 \\
\hline$\geq$ Secondary & 299 & $54 \cdot 8$ & 126 & 55.7 & 142 & $53 \cdot 4$ & 31 & 58.5 & 287 & $54 \cdot 4$ & 12 & $70 \cdot 6$ & 282 & $55 \cdot 0$ & 17 & $53 \cdot 1$ \\
\hline \multicolumn{17}{|l|}{ Employed } \\
\hline No & 433 & 79.5 & 182 & 80.5 & 211 & 79.3 & 40 & 75.5 & 418 & 79.2 & 15 & 88.2 & 411 & 80.1 & 22 & 68.8 \\
\hline Yes & 112 & 20.5 & 44 & 19.5 & 55 & $20 \cdot 7$ & 13 & 24.5 & 110 & $20 \cdot 8$ & 2 & 11.8 & 102 & 19.9 & 10 & 31.2 \\
\hline \multicolumn{17}{|l|}{ Parity } \\
\hline 0 & 491 & 90.3 & 202 & 89.8 & 239 & 89.9 & 50 & 94.3 & 475 & $90 \cdot 1$ & 16 & 94.1 & 461 & 90.0 & 30 & 93.8 \\
\hline 1 & 52 & 9.6 & 22 & 9.8 & 27 & $10 \cdot 2$ & 3 & 5.7 & 51 & 9.7 & 1 & 5.9 & 50 & 9.8 & 2 & $6 \cdot 3$ \\
\hline$\geq 2$ & 1 & 0.2 & 1 & 0.4 & 0 & 0.0 & 0 & 0.0 & 1 & 0.2 & 0 & 0.0 & 1 & 0.2 & 0 & 0.0 \\
\hline Breastfed & 430 & 99.5 & 179 & 99.4 & 216 & 99.5 & 35 & $100 \cdot 0$ & 422 & 99.5 & 8 & $100 \cdot 0$ & 407 & 99.5 & 23 & $100 \cdot 0$ \\
\hline Did not perform physical labour§ & 401 & $75 \cdot 1$ & 172 & 77.1 & 188 & $72 \cdot 9$ & 41 & $77 \cdot 4$ & 387 & 74.9 & 14 & $82 \cdot 4$ & 376 & 74.9 & 25 & $78 \cdot 1$ \\
\hline \multicolumn{17}{|l|}{ LSI $\|$} \\
\hline Lowest & 109 & $20 \cdot 0$ & 49 & 21.7 & 52 & $19 \cdot 6$ & 8 & $15 \cdot 1$ & 108 & 20.5 & 1 & 5.9 & 109 & $21 \cdot 3$ & 0 & 0.0 \\
\hline 2 & 142 & $26 \cdot 1$ & 68 & 30.1 & 65 & 24.4 & 9 & $17 \cdot 0$ & 139 & $26 \cdot 3$ & 3 & $17 \cdot 7$ & 132 & $25 \cdot 7$ & 10 & 31.3 \\
\hline 3 & 147 & $27 \cdot 0$ & 56 & 24.8 & 74 & $27 \cdot 8$ & 17 & $32 \cdot 1$ & 142 & 26.9 & 5 & 29.4 & 139 & $27 \cdot 1$ & 8 & $25 \cdot 0$ \\
\hline Highest & 147 & $27 \cdot 0$ & 53 & 23.4 & 75 & 28.2 & 19 & $35 \cdot 8$ & 139 & $26 \cdot 3$ & 8 & $47 \cdot 1$ & 133 & 25.9 & 14 & 43.7 \\
\hline \multicolumn{17}{|l|}{ Age (years) } \\
\hline Mean & 17 & & 17 & & 17 & & 17 & & 17 & & 17 & & 17 & & 17 & \\
\hline SD & 1.5 & & 1.4 & & 1.5 & & 1.7 & & 1.5 & & $1 \cdot 8$ & & 1.5 & & 1.6 & \\
\hline \multicolumn{17}{|l|}{ Weight (kg) } \\
\hline Mean & 41.4 & & 38.3 & & $42 \cdot 7$ & & 48.5 & & 41.2 & & $48 \cdot 2$ & & $41 \cdot 0$ & & $48 \cdot 1$ & \\
\hline $\mathrm{SD}$ & 4.8 & & 3.5 & & 3.6 & & 4.9 & & 4.6 & & 7.3 & & 4.4 & & 6.0 & \\
\hline \multicolumn{17}{|l|}{ Height $(\mathrm{cm})$} \\
\hline Mean & 148.4 & & 148.5 & & 148.3 & & 148.2 & & 148.4 & & 148.1 & & 148.3 & & 149.3 & \\
\hline SD & 5.4 & & 5.6 & & 5.3 & & 4.5 & & 5.4 & & $5 \cdot 1$ & & 5.3 & & 5.9 & \\
\hline
\end{tabular}

* Of the total analytic sample <20 years old, missing information on these descriptive characteristics was as follows: education $n$ 1; employed $n 1$; parity $n$ 2; breastfeeding $n 114$; physical labour $n 12$; LSI $n$ 1.

$\dagger$ Fat percentage measured by the skinfold thickness method.

(he bioelectrical impedance analysis method.

$\S$ Physical labour was defined as carrying heavy objects or working in the fields or husking grain at least $1 \mathrm{~d}$ during the past week of visit.

|| LSI is expressed as quartiles. 

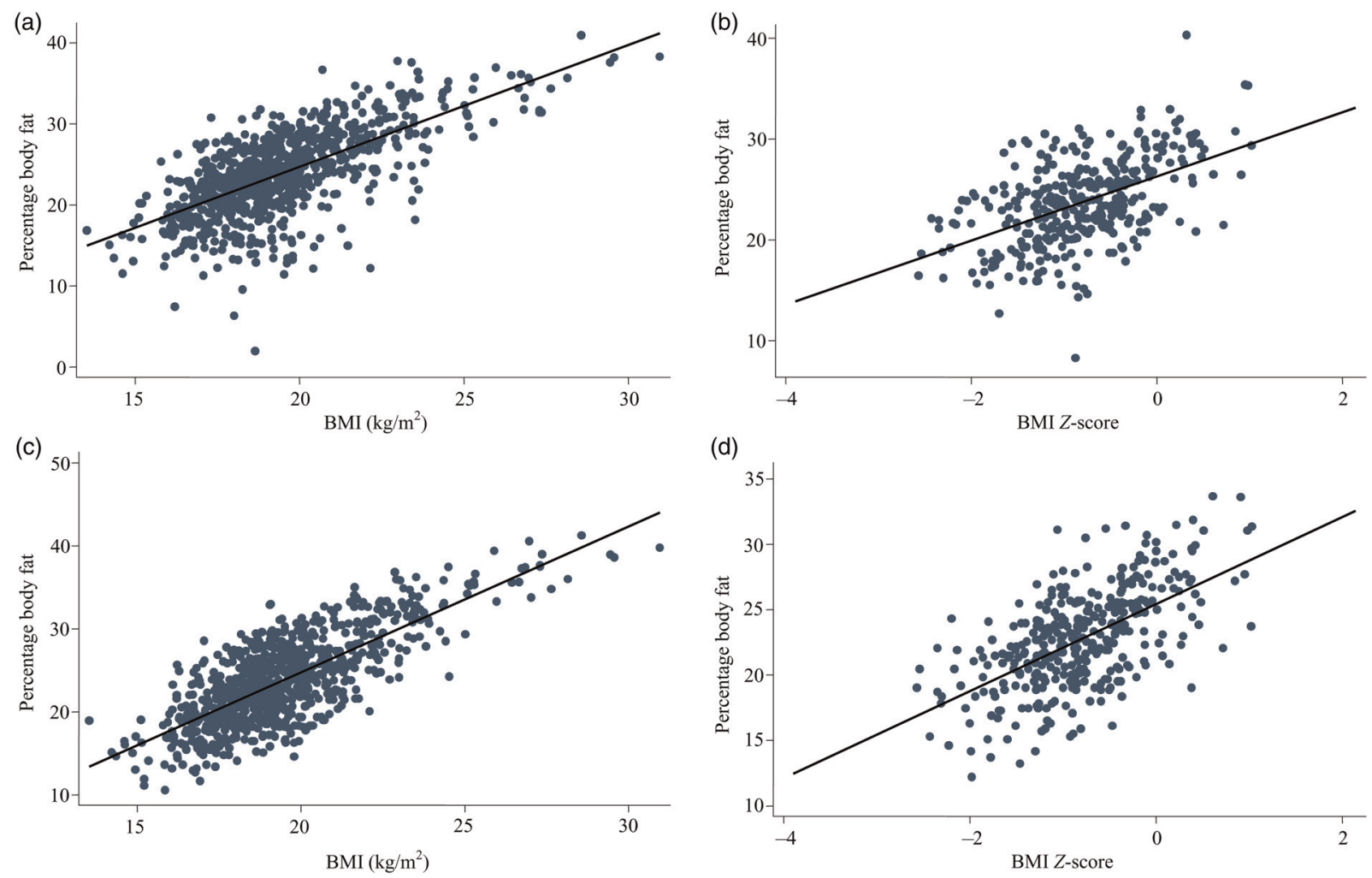

Fig. 1. Scatterplot between BMI and body fat percentage by different methods in different age groups: (a) percentage fat by the bioelectrical impedance analysis (BIA) method in women $\geq 20$ years of age; (b) percentage fat by the BIA method in women <20 years of age; (c) percentage fat by the skinfold method in women $\geq 20$ years of age; (d) percentage fat by the skinfold method in women $<20$ years of age.

$Z$-score of $-0 \cdot 33$ (which corresponds to approximately a BMI of approximately $19.5 \mathrm{~kg} / \mathrm{m}^{2}$ at age 14 years and $20.5 \mathrm{~kg} / \mathrm{m}^{2}$ at age 19 years), which had a sensitivity of $82.4 \%$ and a specificity of $82.2 \%$. AUC was 0.88 (Table 4 and Fig. 2 (c) and (d)). At a BMI of $23 \mathrm{~kg} / \mathrm{m}^{2}$ (WHO Health Action Point for Asian populations), the sensitivity was low $(49 \cdot 2 \%)$ and specificity was high $(98.2 \%)$. Using the $25 \mathrm{~kg} / \mathrm{m}^{2}$ BMI cut-off (WHO cut-off point, 2004), sensitivity was very low (23\%). Among adolescents, using a BMI $Z$-score of $>+1$ SD (the WHO recommended cut-point for overweight) produced a sensitivity of $11.7 \%$ and specificity of $99.8 \%$.

Similar patterns were observed when fat percentage was calculated using BIA. The BMI value that maximised sensitivity and specificity was $20.8 \mathrm{~kg} / \mathrm{m}^{2}$, resulting in a sensitivity of $83.6 \%$ and specificity of $84.2 \%$ among adults (Table 4 ).

Table 3. Simple linear regression of percentage body fat on BMI for adults and adolescents

\begin{tabular}{lccrr}
\hline & BMI coefficients & SE & $R^{2}$ & Constant \\
\hline Study women $\geq 20$ years & & & & \\
$\quad$ Percentage fat by skinfold & 1.8 & 0.05 & 0.59 & -10.50 \\
$\quad$ Percentage fat by BIA & 1.5 & 0.05 & 0.46 & -5.43 \\
Study women <20 years & & & & \\
$\quad$ Percentage fat by skinfold & 3.3 & 0.18 & 0.38 & 25.44 \\
Percentage fat by BIA & 3.2 & 0.21 & 0.29 & 26.30 \\
BMI Z-score squared & 0.41 & 0.18 & 0.30 & \\
\hline
\end{tabular}

BIA, bioelectrical impedance analysis.

${ }^{*} \mathrm{BMI}$ or BMI Z-score squared was tested in each of the models to allow for curvilinearity. It was only statistically significant in the model of women $<20$ years where percentage fat was assessed by BIA.
AUC was 0.92. Among adolescents, the BMI Z-score that maximised specificity and sensitivity was $-0 \cdot 36$, with a sensitivity of $81.3 \%$ and specificity of $80.9 \%$. AUC was 0.87 (Table 4 and Fig. 2(a) and (b)).

\section{Discussion}

This study builds on the limited work that has examined the relationship between BMI and body fat among South Asian

Table 4. Summary of receiver operating characteristic curve analysis of $\mathrm{BMI} / \mathrm{BMI} Z$-score that maximised sensitivity and specificity of body fat classification* among adult and adolescent women

\begin{tabular}{|c|c|c|c|c|}
\hline $\begin{array}{l}\text { Criterion } \\
\text { method }\end{array}$ & $\begin{array}{l}\text { BMI/BMI Z-score } \\
\text { that maximised } \\
\text { sensitivity and } \\
\text { specificity }\end{array}$ & $\begin{array}{c}\text { Sensitivity } \\
(\%)\end{array}$ & $\begin{array}{c}\text { Specificity } \\
(\%)\end{array}$ & AUC \\
\hline \multicolumn{5}{|c|}{ Women $\geq 20$ years (BMI) } \\
\hline $\begin{array}{l}\text { Percentage } \\
\text { fat by skinfold } \\
\text { thickness }\end{array}$ & 20.9 & $86 \cdot 5$ & $87 \cdot 7$ & 0.95 \\
\hline $\begin{array}{l}\text { Percentage } \\
\text { fat by BIA }\end{array}$ & $20 \cdot 8$ & $83 \cdot 6$ & $84 \cdot 2$ & 0.92 \\
\hline \multicolumn{5}{|c|}{ Women <20 years (BMI Z-score) } \\
\hline $\begin{array}{l}\text { Percentage } \\
\text { fat by skinfold } \\
\text { thickness }\end{array}$ & -0.33 & $82 \cdot 4$ & $82 \cdot 2$ & 0.88 \\
\hline $\begin{array}{l}\text { Percentage } \\
\text { fat by BIA }\end{array}$ & -0.36 & $81 \cdot 3$ & $80 \cdot 9$ & 0.87 \\
\hline
\end{tabular}

$\mathrm{BIA}$, bioelectrical impedance analysis.

${ }^{*}$ Normal = percentage fat $\leq 30$; overweight/excess adiposity = percentage fat $>30$. 

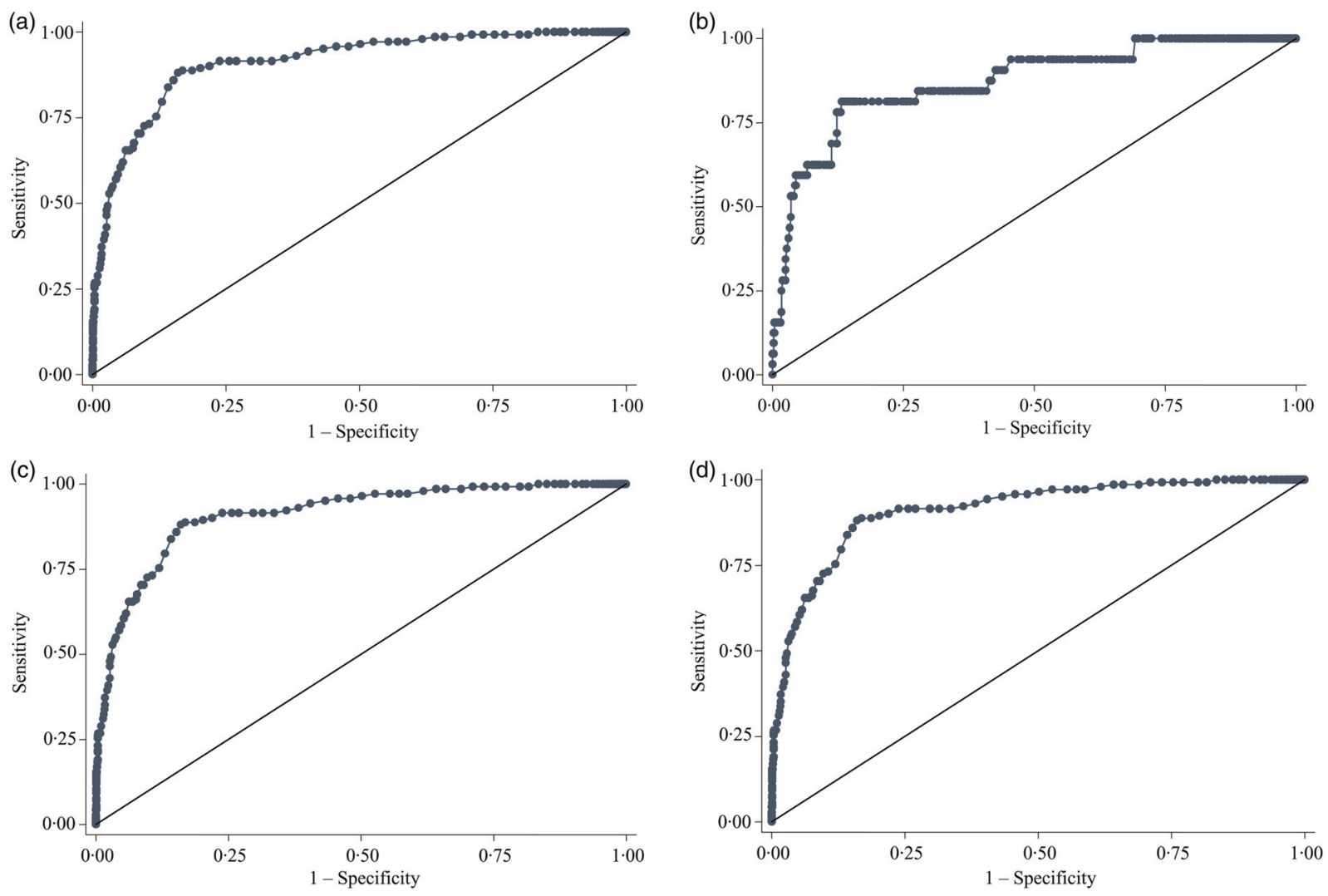

Fig. 2. Receiving operating characteristic curve to determine the appropriate cut-off values of $B M I\left(\mathrm{~kg} / \mathrm{m}^{2}\right)$, while taking percentage body fat as standard: (a) percentage fat by the bioelectrical impedance analysis (BIA) method in women $\geq 20$ years of age; (b) percentage fat by the BIA method in women $<20$ years of age; (c) percentage fat by the skinfold method in women $\geq 20$ years of age; (d) percentage fat by the skinfold method in women $<20$ years of age.

populations, with the goal of evaluating whether existing BMI cut-off points adequately capture excessive body fat in this population. We find that BMI levels corresponding to elevated body fat percentage are remarkably lower in this population than those reported in other Asian and in white European and American populations. Specifically, in our adult population, a BMI of approximately $21 \mathrm{~kg} / \mathrm{m}^{2}$ maximised the sensitivity and specificity of identifying cases of $>30 \%$ body fat, by either skinfold estimates or BIA. This is substantially lower than the WHO Health Action cut-off points (BMI $\geq 23 \mathrm{~kg} /$ $\mathrm{m}^{2}$ ) and the WHO recommended standard cut-off point of $25 \mathrm{~kg} / \mathrm{m}^{2}$. Among adolescents, the analogous value was a BMI $Z$-score of approximately $-0 \cdot 36$, which is also substantially lower than the WHO recommended threshold for overweight $(\geq+1)^{(24)}$.

Our findings are consistent with other researchers who have also observed a higher percentage of body fat in Asian Indians at a comparatively low $\mathrm{BMI}^{(27)}$. This is also consistent with recent findings that South Asians have a lower predicted 'basal BMI', which is the predicted BMI level for a given population under conditions in which the lack of wealth does not allow for the accumulation of fat mass ${ }^{(16,28)}$. Although generally Asian populations tend to have higher body fat at the same level of BMI compared with white American or European populations, it is also widely recognised that there is substantial variation among Asian populations in the level of body fat at the same BMI unit (see Supplementary Tables S1 and S2) ${ }^{(15)}$. For instance, the WHO Working Group found that, among
Asian females, the degree to which BMI was lower for the same level of body fat ranged from less than 0.5 BMI units lower for rural Thai to greater than 3.5 units lower for Hong Kong Chinese. Our study builds on the very small literature examining body fat among South Asians ${ }^{(16,27-29)}$ and improves upon what is known by including a larger sample size and the measurement of body fat by BIA with a validated, population-specific formula for finding percentage body fat. To our knowledge, the only other similar study among South Asians included a small sample of North Indian women ( $n$ 37), in which Dudeja et al. ${ }^{(30)}$ found that a BMI of $19 \mathrm{~kg} / \mathrm{m}^{2}$ maximised sensitivity and specificity of classifying body fat as either normal or high (percentage body fat $\geq 30$ ).

With the worldwide increase in overweight and obesity even among populations that have traditionally suffered primarily from undernutrition it is important to examine whether existing BMI cut-off points adequately capture those with excessive adiposity. Our study suggests that the BMI cut-off points that are typically used to proxy increased adiposity and increased health risks are probably too liberal to capture those with moderately excessive body fat in this South Asian population. However, among this thin population, the areas under the ROC curves were high, indicating that the overall performance of BMI for classifying body fat is quite good. Accordingly, BMI may still be an adequate indicator of excessive fatness in this population if lower cut-off points are applied.

Previous literature provides several hypothesised explanations for the high level of adipose tissue seen at lower BMI 
among Asian populations compared with whites. Visceral adipose tissue tends to be higher in Asian people compared with white Americans or Europeans ${ }^{(31)}$ and a stocky build tends to be characterised by more bone, muscle mass, connective tissue and less body fat than a more slender build ${ }^{(32)}$. A study conducted in an Asian population reported that small stature, lower fat-free mass and more slender body size result in more body fat for the same BMI ${ }^{(33,34)}$ in Asians compared with whites.

Recent studies suggest that there are large differences in basal BMI among ethnic groups and have estimated that South Asian women have one of the lowest basal BMI levels, which indicates muscoskeletal slenderness ${ }^{(16)}$. In terms of what makes some populations have more slender builds, physical anthropologists have theorised that climate conditions may drive the slenderness $v$. stockiness of populations ${ }^{(35)}$. Additionally, recent work has shown that genetic ancestry group explains a substantial proportion of the variance in slenderness between populations ${ }^{(36)}$. In addition, in utero and developmental conditions, dietary composition and physical activity may play roles in determining slender builds ${ }^{(28)}$.

Strengths of the present study are that body fat percentage was measured by two methods (skinfold and BIA), the two methods were in agreement on mean percentage body fat in the study sample, and that the sample size was large. A limitation of the study is that both the skinfold and the BIA methods for calculating percentage body fat require at least one reference method, though the BIA equation used to calculate fat-free mass was developed against ${ }^{2} \mathrm{H}_{2} \mathrm{O}$ dilution for this population ${ }^{(17)}$. These women were 3 months postpartum; however, in this sample we have previously shown that by 3 months postpartum, women are back to their pre-pregnancy BMI and body composition status, including reactance and resistance for height ${ }^{(16)}$. Further research is needed in this population to calculate percentage body fat using reference methods, i.e. underwater weighing, dual-energy X-ray absorptiometry or air displacement plethysmography. Additionally, future research should further examine how non-communicable disease outcomes or intermediate biomarkers are associated with body fat as well as BMI in this population.

In conclusion, traditional BMI cut-offs of 23 and $25 \mathrm{~kg} / \mathrm{m}^{2}$ had low sensitivity for identifying cases of moderately excessive body fat in rural Bangladeshi women. Our results suggest that BMI can be a diagnostic tool in this population if a substantially lower cut-off of $21 \mathrm{~kg} / \mathrm{m}^{2}$ is used.

\section{Supplementary material}

The supplementary material for this article can be found at http://www.journals.cambridge.org/10.1017/jns.2015.32

\section{Acknowledgements}

The present work was supported by grant GH OPP614 (Global Control of Micronutrient Deficiency) from the Bill and Melinda Gates Foundation, Seattle, WA, and Global Research Activity Cooperative Agreement (GHS-A-00-0300019-00) and Micronutrients for Health Cooperative
Agreement (HRN-A-00-97-00015) between Johns Hopkins University and the Office of Health, Infectious Disease and Nutrition, US Agency for International Development (USAID), Washington, DC, International Atomic Energy Agency (IAEA) and Bangladesh Atomic Energy Commission (BAEC) and the Sight and Life Research Institute, Baltimore, MD, USA. J. J.-S. was supported by the Eunice Kennedy Shriver National Institute of Child Health and Human Development (U54HD070725).

We gratefully acknowledge the JiVitA field staff and data management teams and Johns Hopkins collaborators (Allan Massie and Maithilee Mitra) for their contribution. We want to give special thanks to the women who had participated in the study.

The contributions of the authors to the study were as follows: S. S. conceptualised the project, operationalised the study, analysed data and drafted the manuscript; J. J.-S. aided in the data analysis and drafting of the manuscript, K. S. and S. M. aided in the design of the study and data collection planning; H. A. aided in the design of the study and oversaw field operations, subject recruitment and participation; A. A. S. and M. R. aided in the design of the study and provided scientific and administrative oversight of the main trial and this substudy; A. L. and R. K. aided in the design and implementation of the study and oversaw the study design; L. W. aided in the data analysis; P. C. and K. P. W. were the principal investigators for the main trial, provided scientific oversight and provided critical intellectual content on the work. All authors provided critical intellectual feedback on and approved the final manuscript.

The authors declare no conflict of interest.

\section{References}

1. Field AE, Coakley EH, Must A, et al. (2001) Impact of overweight on the risk of developing common chronic diseases during a 10-year period. Arch Intern Med 161, 1581-1586.

2. Mokdad AH, Ford ES, Bowman BA, et al. (2003) Prevalence of obesity, diabetes, and obesity-related health risk factors, 2001. JAMA 289, 76-79.

3. Al Snih S, Ottenbacher KJ, Markides KS, et al. (2007) The effect of obesity on disability vs mortality in older Americans. Arch Intern Med 167, 774-780.

4. Whitlock G, Lewington S, Sherliker P, et al. (2009) Body-mass index and cause-specific mortality in 900000 adults: collaborative analyses of 57 prospective studies. Lancet 373, 1083-1096.

5. Finucane MM, Stevens GA, Cowan MJ, et al. (2011) National, regional, and global trends in body-mass index since 1980: systematic analysis of health examination surveys and epidemiological studies with 960 country-years and 9.1 million participants. Lancet 377, 557-567.

6. Balarajan Y \& Villamor E (2009) Nationally representative surveys show recent increases in the prevalence of overweight and obesity among women of reproductive age in Bangladesh, Nepal, and India. J Nutr 139, 2139-2144.

7. Shafique S, Akhter N, Stallkamp G, et al. (2007) Trends of underand overweight among rural and urban poor women indicate the double burden of malnutrition in Bangladesh. Int J Epidemiol 36, 449-457.

8. World Health Organization (2014) Disease and injury country estimates, 2008. http://www.who.int/healthinfo/global_burden_ disease/estimates_country/en/index.html (accessed November 2015). 
9. Sayeed MA, Mahtab H, Akter Khanam P, et al. (2003) Diabetes and impaired fasting glycemia in a rural population of Bangladesh. Diabetes Care 26, 1034-1039.

10. Rahim MA, Azad Khan AK, Sayeed MA, et al. (2007) Metabolic syndrome in rural Bangladesh: comparison of newly proposed IDF, modified ATP III and WHO definition and their agreements. Diabetes Metab Syndr Clin Res Rev 1, 251-257.

11. Rahim MA, Hussain A, Azad Khan AK, et al. (2007) Rising prevalence of type 2 diabetes in rural Bangladesh: a population based study. Diabetes Res Clin Pract 77, 300-305.

12. Saquib N, Saquib J, Ahmed T, et al. (2012) Cardiovascular diseases and type 2 diabetes in Bangladesh: a systematic review and meta-analysis of studies between 1995 and 2010. BMC Public Health 12, 434.

13. Yajnik C, Fall C, Coyaji K, et al. (2003) Neonatal anthropometry: the thin-fat Indian baby. The Pune Maternal Nutrition Study. Int J Obes Relat Metab Disord 27, 173-180.

14. Durnin JV \& Womersley J (1974) Body fat assessed from total body density and its estimation from skinfold thickness: measurements on 481 men and women aged from 16 to 72 years. Br J Nutr 32, 77-97.

15. WHO Expert Committee (2004) Appropriate body-mass index for Asian populations and its implications for policy and intervention strategies. Lancet 363, 157-163.

16. Hruschka DJ, Rush EC \& Brewis AA (2013) Population differences in the relationship between height, weight, and adiposity: an application of Burton's model. Am J Phys Anthropol 151, 68-76.

17. Shaikh S, Schulze KJ, Ali H, et al. (2011) Bioelectrical impedance among rural Bangladeshi women during pregnancy and in the postpartum period. J Health Popul Nutr 29, 236-244.

18. West KP, Christian P, Labrique AB, et al. (2011) Effects of vitamin A or beta carotene supplementation on pregnancy-related mortality and infant mortality in rural Bangladesh: a cluster randomized trial. JAMA 305, 1986-1995.

19. Shaikh S, Schulze KJ, Kurpad A, et al. (2013) Development of bioelectrical impedance analysis-based equations for estimation of body composition in postpartum rural Bangladeshi women. $\mathrm{Br} J$ Nutr 109, 639-647.

20. Ulijaszek SJ \& Kerr DA (1999) Anthropometric measurement error and the assessment of nutritional status. Br J Nutr 82, 165-177.

21. Siri WE (1956) The gross composition of the body. Adv Biol Med Phys 4, 239-280.

22. Wang Z, Deurenberg P, Wang W, et al. (1999) Hydration of fat-free body mass: new physiological modeling approach. Am J Physiol 276, E995-E1003.
23. Wang Z, Deurenberg P, Wang W, et al. (1999) Hydration of fat-free body mass: review and critique of a classic body-composition constant. Am J Clin Nutr 69, 833-841.

24. de Onis M, Onyango AW, Borghi E, et al. (2007) Development of a WHO growth reference for school-aged children and adolescents. Bull WHO 85, 660-667.

25. Deurenberg P, Weststrate JA \& Seidell JC (1991) Body mass index as a measure of body fatness: age- and sex-specific prediction formulas. Br J Nutr 65, 105-114.

26. Hanley JA (1988) The robustness of the "binormal" assumptions used in fitting ROC curves. Med Decis Making 8, 197-203.

27. Rush EC, Freitas I \& Plank LD (2009) Body size, body composition and fat distribution: comparative analysis of European, Maori, Pacific Island and Asian Indian adults. BrJ Nutr 102, 632-641.

28. Hadley C \& Hruschka DJ (2014) Population level differences in adult body mass emerge in infancy and early childhood: evidence from a global sample of low and lower-income countries. $A m \mathrm{~J}$ Phys Anthropol 154, 232-238.

29. Rush EC, Obolonkin V, Battin M, et al. (2015) Body composition in offspring of New Zealand women: ethnic and gender differences at age 1-3 years in 2005-2009. Ann Hum Biol 42, 498-503.

30. Dudeja V, Misra A, Pandey R, et al. (2001) BMI does not accurately predict overweight in Asian Indians in northern India. Br J Nutr 86 , 105-112.

31. Park YW, Allison DB, Heymsfield SB, et al. (2001) Larger amounts of visceral adipose tissue in Asian Americans. Obes Res 9, 381-387.

32. Norgan NG (1994) Population differences in body composition in relation to BMI. Eur J Clin Nutr 48 (Suppl. 3), S10-S27.

33. Lohman TG (1992) Advances in Body Composition Assessment. Current Issues in Exercise Science (Monograph no. 3). Champaign, IL: Human Kinetics Publishers.

34. Chang CJ, Wu CH, Chang CS, et al. (2003) Low body mass index but high percent body fat in Taiwanese subjects: implications of obesity cutoffs. Int J Obes Relat Metab Disord 27, 253-259.

35. Leonard WR \& Katzmarzyk PT (2010) Body size and shape: climatic and nutritional influences on human body morphology. In Human Evolutionary Biology, pp. 157-169 [MP Muehlenbeinn, editor]. Cambridge, UK: Cambridge University Press.

36. Hruschka DJ, Hadley C, Brewis AA, et al. (2015) Genetic population structure accounts for contemporary ecogeographic patterns in tropic and subtropic-dwelling humans. PLOS ONE 10, e0122301. 